\title{
Prostate Cancer Risk in Relation to CYP3A4 and CYP3A5 Genotypes in the Bangladeshi Population
}

\author{
Sm Faysal Bellah ${ }^{1}$, Maizbha Uddin Ahmed ${ }^{1}$, Sikder Nahidul Islam Rabbi ${ }^{2}$, \\ Mohd Nazmul Hasan Apu ${ }^{1}$, Md. Siddiqul Islam ${ }^{1}$, Mir Muhammad Nasir Uddin ${ }^{3}$, \\ Mohammad Safiqul Islam ${ }^{4}$ and Abul Hasnat ${ }^{1}$
}

\author{
${ }^{1}$ Department of Clinical Pharmacy and Pharmacology, Faculty of Pharmacy, University of Dhaka, Dhaka-1000, Bangladesh \\ ${ }^{2}$ Pharmacogenetics lab, Labaid Cardiac and specialized Hospital, Dhanmondi, Dhaka 1205, Bangladesh \\ ${ }^{3}$ Department of Pharmacy, University of Chittagong, Chittagong-4331, Bangladesh \\ ${ }^{4}$ Department of Pharmacy, Noakhali Science and Technology University, Sonapur, Noakhali-3814, Bangladesh
}

Received: January 03, 2016; Accepted: January 24, 2016; Published (web): January 31, 2016

\begin{abstract}
Genetic polymorphism on CYP3A4 and CYP3A5 gene and their associational susceptibility to prostate cancer was studied on Bangladeshi population, considering the importance of CYP3A4 and CYP3A5 gene in detoxification of xenobiotics from physiological territory. In this case control regulated study, we focused on two allelic variants CYP3A4 rs2740574 (CYP3A4*1B) and CYP3A5 rs776746 (CYP3A5*3) applying Polymerase Chain Reaction (PCR)-Restriction Fragment Length Polymorphism (RFLP). Associational risk on prostate cancer was estimated as odds ratio (OR) and $95 \%$ confidence interval (CI) using unconditional logistic regression models. An elevated prostate cancer risk was found with heterozygous, mutant and heterozygous plus mutant variants of CYP3A4*1B which is not statistically significant $(p>0.05)$, whereas a significant association was found with heterozygous, mutant and heterozygous plus mutant variants of $\mathrm{CYP} 3 \mathrm{~A} 5 * 3(\mathrm{OR}=4.36,95 \% \mathrm{CI}=1.53$ to $12.38, \mathrm{P}$ $=0.003 ; \mathrm{OR}=3.85,95 \% \mathrm{CI}=1.19$ to $12.43, \mathrm{P}=0.017$ and $\mathrm{OR}=4.13,95 \% \mathrm{CI}=1.84$ to $9.28, \mathrm{p}=0.0006$ respectively). The findings signposted a significant association of CYP3A $5 * 3$ gene and nullify the association of CYP3A4*1B gene's polymorphism with prostate cancer risk in Bangladeshi subject.
\end{abstract}

Key words: CYP3A4, CYP3A5, prostate cancer, Bangladeshi population

\section{INTRODUCTION}

Prostate Cancer (PCa) has been the most common cancer in the world for several decades, and by 2012, the estimated cases were 1112,000 representing the $15 \%$ of the cancers diagnosed in men whereas the estimated deaths were 307,000 and it was the fifth leading cause of death from cancer in men $\left(6.6 \%\right.$ of the total men deaths). ${ }^{1}$ The estimated incidence and mortality of prostate cancer in Bangladesh were 923 and 717 in 2012 and that will be 1810 and 1342 in 2030, respectively. ${ }^{1} \mathrm{PCa}$ is one

Correspondence to: Abul Hasnat

Tel: +88-02-9667850; Fax No: +88-02-8615583

E-mail: ahasnat@ du.ac.bd

Dhala Univ. J. Pharm. Sci. 14(2): 179-185, 2015 (December) of the leading causes of cancer death in men, and both genetic and environmental factors have been shown to be important for the development of this disease..$^{2-5}$ Prostate cancer can grow in an androgendependent pathway by the activation of androgen and about $95 \%$ of prostate tumors develop from the luminal cells. There are three distinct glandular regions in the human prostate gland such as peripheral, central, and transitional zone comprising $70 \%, 30 \%$, and $5 \%$ of the normal glandular prostate mass respectively. ${ }^{6}$ Large percentage of $\mathrm{PCa}$ is due to the presence of common polymorphisms whereas family history is responsible only $5-10 \%$ of prostate cancers. $^{7,8}$ Recently, researchers have focused on the role of genes involved in the metabolism, 
biosynthesis, and regulation of androgens in the occurrence and progression of prostate cancer. The CYP family of enzymes plays a vital role in a wide variety of metabolic pathways involving both endogenous and exogenous substances ${ }^{9}$ and the metabolism of steroids, as well as environmental xenobiotics may have significant influence on prostate cancer. $^{7-9}$ CYP3A4 belongs to the cytochrome P-450 supergene family is involved in the metabolism and most likely the deactivation of testosterone. ${ }^{10,11}$ It has been reported that, the genetic variant in the 59 regulatory region of the CYP3A4 gene (A to $G$ transition at position 2293 from the ATG start site) is associated with prostate cancer. ${ }^{12}$ CYP3A4 is involved in oxidation of testosterone to $2 \beta-, 6 \beta-$, or $15 \beta$-hydroxytestosterone. ${ }^{10}$ It has been postulated that the presence of the CYP3A4*1B allele decreases the amount of CYP3A4 protein, leading to a reduction of testosterone metabolism and therefore more availability of testosterone for conversion to dihydrotestosterone, the most potent androgen affecting the growth and differentiation of prostate cells. ${ }^{13}$ However, several studies failed to link up the activity of the CYP3A4*1B with $\mathrm{PCa} .{ }^{14-17}$ It was found that Caucasian carriers of CYP3A4*1B had a higher Tumor-Node-Metastasis stage and Gleason grade than the non-carriers. ${ }^{18-20}$ On the other hand the CYP3A5*1 variant was inversely associated with prostate cancer, especially among Caucasians with less aggressive disease. ${ }^{20}$ One researcher reported that minor allele frequencies of Korean population were similar with those of the Japanese and Han Chinese populations, whereas distinct differences were found from European-Americans or African-Americans. Among the pharmacogenetic markers frequencies of CYP3A4*1B (rs2740574) and CYP3A5*3C (rs776742) in Asian groups were different from those in other populations. ${ }^{21}$ This study was designed to find out the relationship of CYP3A4rs2740574 and CYP3A5rs776746 polymorphisms with Bangladeshi prostate cancer patients.

\section{MATERIALS AND METHODS}

Study design. This case-control study was conducted on 100 prostate cancer patients and 100 healthy volunteers matched by age, sex and smoking status. Prostate cancer patients were recruited from Ahsania Mission Cancer and General Hospital $(\mathrm{AMCH})$, Dhaka Medical College Hospital (DMCH) and Bangabandhu Sheikh Mujib Medical University (BSMMU), Dhaka, Bangladesh. Patients were histologically diagnosed with prostate cancer between the period of January 2011 and December 2012. The Institutional Review Boards of the mentioned hospitals approved the study design. The clinical characteristics, including Gleason grade, PSA, and TNM stage, as well as other potentially important factors, such as age at diagnosis and family history of prostate cancer were recorded during the study. Tumor grade was determined according to the Gleason system ${ }^{22-24}$ whereas the tumor stage was determined after review of the microscopic sections of the specimen. ${ }^{25}$ All cases were histologically confirmed and underwent radical prostatectomy, transurethral resection of the prostate, or prostatic biopsy. Smoking information, demographic characteristics, and lifestyle factors were collected through interviews by trained nurses in the presence of expert physicians. Prostate cancer cases had a history or evidence of any other severe diseases like cardiovascular disease, kidney disease; previous cancer and metastasized cancer were excluded from the study. Controls were not relatives to the patients and no subject had a history or evidence of hepatic, renal, gastrointestinal or hematologic deviations or any acute or chronic diseases based on medical history, clinical examination and laboratory investigation (hematology, blood biochemistry and urine analysis). The study was conducted in accordance with the declaration of Helsinki and its subsequent revisions. ${ }^{26}$

Genomic DNA isolation and genotyping. Venous blood ( $3 \mathrm{ml}$ ) was collected from all cases and controls in sterile tubes containing EDTA- $\mathrm{Na}_{2}$ and stored at $-80{ }^{\circ} \mathrm{C}$ until DNA extraction. Genomic DNA was extracted from blood samples of all 
subjects according to our previous method. ${ }^{27-30}$ For genotyping, PCR-RFLP was employed due to its affordability, ease of use and reliability. CYP3A4*1B, CYP3A5*3 were genotyped by previously described method. ${ }^{27,30}$ The primers, PCR conditions, and restriction enzymes are presented in table 1. A $25 \mu \mathrm{l}$ PCR reaction volume was used, containing $1 \mu \mathrm{l}$ of genomic DNA (50-70 ng/ $\mu \mathrm{l}), 5 \mu \mathrm{l}$ of 5x GoTaq reaction buffer, $4 \mu \mathrm{l}$ of $\mathrm{MgCl}_{2}(25 \mathrm{mM})$, $2 \mu \mathrm{l}$ of dNTPs $(2.5 \mathrm{mM}), 1 \mu \mathrm{l}$ of each primer $(10 \mu \mathrm{M})$, $0.1 \mu \mathrm{l}$ of GoTaq DNA polymerase $(5 \mathrm{U} / \mu \mathrm{l})$ (Promega Corporation, USA), and $10.9 \mu \mathrm{l}$ of nuclease free water. PCR products were analyzed on a $2 \%$ agarose gel by staining with ethidium bromide. After PCR amplification, $20 \mu \mathrm{l}$ PCR products were digested (overnight at $37{ }^{\circ} \mathrm{C}$ ) with approximately 2 units of MboII and RsaI for CYP3A4*1B and CYP3A5*3 respectively. Electrophoresis was done for restriction enzyme digested products using $3 \%$ agarose gel in $1 \mathrm{x}$ TAE buffer or $10 \%$ polyacrylamide gels in $1 \mathrm{x}$ TBE buffer. Samples found heterozygous and mutant homozygous were analyzed twice and subject to direct sequencing by using our previous reported method. ${ }^{27-30}$

Table 1. Primers, PCR conditions, restriction enzymes (RE) and expected DNA fragments on digestion to genotype the selected polymorphisms.

\begin{tabular}{|c|c|c|c|c|}
\hline Allele & Primer sequence & PCR (35 cycles) & $\mathrm{RE}$ & DNA fragments \\
\hline CYP3A4*1B & $\begin{array}{l}\text { FP 5'-GAATGAGGACAGCCATAGAGACAAGGGGA- } \\
\text { 3'RP 5'-CCTTTCAGCTCTGTGTTGCTCTTTGCTG-3' }\end{array}$ & $\begin{array}{l}94^{\circ} \mathrm{C} 1 \mathrm{~min} \\
57^{\circ} \mathrm{C} 1 \mathrm{~min} \\
72^{\circ} \mathrm{C} 1 \mathrm{~min}\end{array}$ & MboII & $\begin{array}{l}\text { AF } 385 \\
\text { NH } 175,169,41 \\
\text { HE } 210,175,169,41 \\
\text { MH 210, } 175\end{array}$ \\
\hline CYP3A5*3 & $\begin{array}{l}\text { FP 5'-CCTGCCTTCAATTTTTCACT-3' } \\
\text { RP 5'- GTCCAAACAGGGAAGAGGT-3' }\end{array}$ & $\begin{array}{l}94{ }^{\circ} \mathrm{C} 1 \mathrm{~min} \\
59{ }^{\circ} \mathrm{C} 1 \mathrm{~min} \\
72^{\circ} \mathrm{C} 1 \mathrm{~min}\end{array}$ & RsaI & $\begin{array}{l}\text { AF } 196 \\
\text { NH } 102,74,20 \\
\text { HE } 102,94,74,20 \\
\text { MH } 102,94\end{array}$ \\
\hline
\end{tabular}

Statistical analysis. Distributions of demographic variables were compared between cases and controls using $\chi 2$ - tests and two-sided unpaired ttests. Genotype and allelic frequencies were reported as percentage and the distribution of genotype frequency was also compared by $\chi^{2-}$ test. Unconditional logistic regression was used to estimate crude odds ratio (OR) and their 95\% confidence intervals (CIs) using the statistical software package SPSS version 20.0 (SPSS, Inc., Chicago, IL).

\section{RESULTS AND DISCUSSION}

Cases and controls characteristics and histological subtype of prostate cancer. The distributions of demographic characteristics and clinical data among study subjects were summarized in table 2. The related factors such as age and smoking history of cases and controls were compared to confirm that the observed effects were solely due to the genotype frequency. There were no significant differences in mean age $(\mathrm{p}=0.776)$ and smoking status $(\mathrm{p}=0.788)$ between the two groups.

Among 100 cases, the histological subtypes of prostate cancer were $19 \%$ of weak anaplasia (Gleason $2-4$ ), $18 \%$ of moderate anaplasia (Gleason 5-6) and $63 \%$ of marked anaplasia (Gleason $7-10$ ). The mean and range of prostate specific antigen $(\mathrm{ng} / \mathrm{dl})$ is 56 and (20-176) respectively (Table 2).

Smoking status. The observed never smoking rate was $7 \%$ in the cases and $8 \%$ in controls. Among the smokers $65 \%$ and $21 \%$ were current and exsmokers in cases and were $69 \%$ and $20 \%$ in controls, respectively. The rates of chewing tobacco were $7 \%$ and $3 \%$ in cases and controls respectively. There is no significant difference between current smoker, ex-smoker, never smokers and chewing tobacco groups between cases and controls ( $\mathrm{p}=$ 0.788) (Table 2). 
CYP3A4 polymorphisms. The genotypes of CYP3A4*1B in both cases and controls were presented in table 3 . There was no significant difference found among the genotypes of cases and controls $(\mathrm{p}=0.356)$. Compared with the wild type genotype, patients carrying heterozygous, mutant homozygous and combined heterozygous plus mutant homozygous of CYP3A4rs2740574 showed increased risk of prostate cancer $(\mathrm{OR}=2.46,95 \% \mathrm{CI}$ $=0.62$ to $9.81, \mathrm{p}=0.202 ; \mathrm{OR}=2.11,95 \% \mathrm{CI}=$ 0.19 to $23.67, \mathrm{p}=0.545$ and $\mathrm{OR}=2.37,95 \% \mathrm{CI}=$ 0.71 to $7.98, p=0.162$, respectively) and that were not statistically significant.

Table 2. Distribution of demographic variables of the prostate cancer patients and controls.

\begin{tabular}{lccc}
\hline Variables & Cases $(\mathrm{n}=100)(\%)$ & Controls $(\mathrm{n}=100)(\%)$ & P-value \\
\hline Age (years) & $66( \pm 2.6)$ & $66( \pm 2.7)$ & $0.7^{\mathrm{a}}$ \\
Mean age, $\mathrm{n}( \pm \mathrm{SD})$ & $63-72$ & $62-72$ & \\
Range & & & - \\
Smoking status, $\mathrm{n}(\%)$ & 65 & 69 & \\
Current smoker & 21 & 3 & $0.7^{\mathrm{b}}$ \\
Ex-smoker & 7 & 8 & \\
Chewing tobacco & 7 & 92 & - \\
Never smoker & 93 & & \\
Total tobacco user & 7 & - & \\
Total tobacco nonuser & & & \\
Histological type, $\mathrm{n}(\%)$ & 16 & \\
Weak anaplasia: Gleason 2-4 & 18 & \\
Moderate anaplasia: Gleason 5-6 & 63 & & \\
Marked anaplasia: Gleason 7-10 & & & - \\
Prostate Specific Antigen (ng/dl) & $56( \pm 31.1)$ & \\
Mean ( \pm SD) & $20-176$ & & \\
Range & & & \\
\hline
\end{tabular}

${ }^{\mathrm{a}}$ Unpaired t test, ${ }^{\mathrm{b}} \chi^{2}$ test.

CYP3A5 polymorphisms. The genotypes of CYP3A5 in both cases and controls were presented in Table 3. Significant difference $(\mathrm{p}=0.001)$ among the genotype frequencies of cases and controls was found in the cases and controls. Compared with the wild genotype, patients carrying heterozygous, mutant homozygous and combined heterozygous plus mutant homozygous of CYP3A5rs776746 showed significant association with the risk of prostate cancer $(\mathrm{OR}=4.36,95 \% \mathrm{CI}=1.53$ to $12.38, \mathrm{p}=0.003 ; \mathrm{OR}=$ $3.85,95 \% \mathrm{CI}=1.19$ to $12.43, \mathrm{p}=0.017$ and $\mathrm{OR}=$ $4.13,95 \% \mathrm{CI}=1.84$ to $9.28, \mathrm{p}=0.0006$ respectively).

In this study, we tried to find out the association between CYP3A4*1B and CYP3A5*3 polymorphisms and prostate cancer risk in
Bangladeshi population. It is the first of such kind of epidemiological study on Bangladeshi population. We focused on prostate cancer, as it is one of the most prevalent causes of cancer related death in Bangladesh. There were no significant differences in mean age $(\mathrm{p}=0.776)$ and smoking status $(\mathrm{p}=0.788)$ between the two groups (Table 2).

Our results revealed that, the genotype of CYP3A4*1B variant has increased risk but not significantly associated $(\mathrm{p}>0.05)$ with prostate cancer (Table 3). Unfortunately, we had limited ability to obtain statistical significance because of small sample size low frequency of this allele in the study population. Our finding is consistent with some studies conducted on other Asians ${ }^{31-33}$ and similar finding was also observed in non- Asians 
population. $^{13,18,19}$ Several researchers found an inverse association between CYP3A4*1B and prostate cancer risk. ${ }^{34,35}$ One study conducted on South African White and Mixed Ancestry men where a positive association $(\mathrm{p}<0.05)$ was observed between the $\mathrm{AG}$ and $\mathrm{AG} / \mathrm{GG}$ genotypes of CYP3A4rs2740574 and $\mathrm{PCa}^{36} \mathrm{~A}$ number of researchers investigated the effects of CYP3A4*1B in protein expression or function ${ }^{14,16,37-41}$ and the majority of the studies reported elevation of CYP3A4 levels in the presence of $\mathrm{G}$ carrier genotypes. However, most of the authors reported a small magnitude of association of CYP3A4 and CYP3A5 with prostate cancer prognosis ${ }^{37}$ and almost all studies have reported consistent elevations in expression associated with CYP3A4*1B in the range of $20-200 \%$ increase over the consensus CYP3A4*1A. ${ }^{34}$ In this case control study we found a significant elevated risk of prostate cancer with CYP3A5*3 genotypes that is consistent with one previous report. ${ }^{42}$ Some researchers also found opposite result that is may be due to the uniqueness of the ancestry of the Indian subcontinent. ${ }^{36,42,43}$ This study is on the Bangladeshi population that was also a part of Indian subcontinent earlier and no study was yet reported with the mentioned genes on native Indian prostate cancer patients.

Table 3. CYP3A4*1B and CYP3A5*3 genotypes and allelic frequencies among prostate cancer cases and controls.

\begin{tabular}{|c|c|c|c|c|c|}
\hline & Cases $(\%)$ & Controls $(\%)$ & OR & $95 \% \mathrm{CI}$ & $P$ \\
\hline \multicolumn{6}{|c|}{ CYP3A4*1B genotype } \\
\hline$* 1 \mathrm{~A} / * 1 \mathrm{~A}$ & 91 & 96 & 1 & -- & -- \\
\hline$* 1 \mathrm{~A} / * 1 \mathrm{~B}$ & 7 & 3 & 2.46 & 0.62 to 9.81 & 0.202 \\
\hline$* 1 \mathrm{~B} / * 1 \mathrm{~B}$ & 2 & 1 & 2.11 & 0.19 to 23.67 & 0.545 \\
\hline$* 1 \mathrm{~A} / * 1 \mathrm{~B}+* 1 \mathrm{~B} / * 1 \mathrm{~B}$ & 9 & 4 & 2.37 & 0.71 to 7.98 & 0.162 \\
\hline \multicolumn{6}{|l|}{ CYP3A4 allele } \\
\hline CYP3A4*1A & 189 & 195 & 1 & -- & -- \\
\hline CYP3A4*1B & 11 & 5 & 2.27 & 0.77 to 6.66 & 0.135 \\
\hline \multicolumn{6}{|l|}{ CYP3A5*3 genotype } \\
\hline$* 1 / * 1$ & 71 & 91 & 1 & -- & -- \\
\hline$* 1 / * 3$ & 17 & 5 & 4.36 & $1.53-12.38$ & 0.003 \\
\hline$* 3 / * 3$ & 12 & 4 & 3.85 & $1.19-12.43$ & 0.017 \\
\hline$* 1 / * 3+* 3 / * 3$ & 29 & 9 & 4.13 & $1.84-9.28$ & 0.0006 \\
\hline \multicolumn{6}{|l|}{ CYP3A5 allele } \\
\hline CYP3A5*1 & 159 & 187 & 1 & -- & -- \\
\hline CYP3A $5 * 3$ & 41 & 13 & 3.7 & $1.92-7.17$ & 0.0001 \\
\hline
\end{tabular}

$\mathrm{OR}=$ Odds ratio, $\mathrm{CI}=$ Confidence interval

\section{CONCLUSION}

We investigated the effect of CYP3A4*1B and CYP3A5*3 as risk factors for the development of prostate cancer among Bangladeshi population. Our observation stated that CYP3A4*1B polymorphism is not significantly associated with increased risk for prostate cancer whereas CYP3A $5 * 3$ is significantly associated with the risk of prostate cancer in the study subject of Bangladeshi population.

\section{ACKNOWLEDGMENTS}

The authors are thankful to all the staffs, nurses, and physicians of Ahsania Mission Cancer and General Hospital (AMCH), Dhaka Medical College Hospital (DMCH) and Bangabandhu Sheikh Mujib Medical University (BSMMU), Dhaka, Bangladesh and the participants of this study. 


\section{REFERENCES}

1. Ferlay, J., Soerjomataram, I., Ervik, M., Dikshit, R., Eser, S., Mathers, C., Rebelo, M., Parkin, D.M., Forman, D. and Bray, F. 2013. GLOBOCAN 2012 v1.0, Cancer Incidence and Mortality Worldwide: IARC CancerBase No. 11 [Internet]. Lyon, France: International Agency for Research on Cancer.

2. Novelli, G., Margiotti, K., Chiocca, AM., Spera, E. and Micali, F. 2004. Pharmacogenetics of human androgens and prostate cancer-an update. Pharmacogenomics 5, 283-294.

3. Center, M.M., Jemal, A., Lortet-Tieulent, J., Ward, E., Ferlay, J. and Brawley, O. 2012. International variation in prostate cancer incidence and mortality rates. Eur Urol. 61,1079-1092.

4. Jemal, A., Bray, F., Center, M.M., Ferlay, J. and Ward, E. 2011. Global cancer statistics. CA Cancer J. Clin. 61, 69-90.

5. Ferlay, J., Shin, H.R., Bray, F., Forman, D. and Mathers, C. 2010. Estimates of worldwide burden of cancer in 2008: GLOBOCAN 2008. Int. J. Cancer, 127, 2893-917.

6. Villers, A., Steg, A. and Boccon-Gibod, L. 1991. Anatomy of the prostate: review of the different models. Eur. Urol. 20, 261-268.

7. Coughlin, S.S. and Hall, I.J. 2002. A review of genetic polymorphisms and prostate cancer risk. Ann. Epidemiol. 12, 182-196.

8. Nwosu, V., Carpten, J., Trent, J.M. and Sheridan, R. 2001. Heterogeneity of genetic alterations in prostate cancer: evidence of the complex nature of the disease. Hum. Mol. Genet. 10, 2313-2318.

9. Gibson, G.G., Plant, N.J., Swales, K.E. and Ayrton, A. 2002. Receptor-dependent transcriptional activation of cytochrome P4503A genes: induction mechanisms, species differences and inter-individual variation in man. Xenobiotica 32, 165206.

10. Waxman, D.J., Attisano, C., Guengerich, F.P. and Lapenson, D.P. 1988. Human liver microsomal steroid metabolism: identification of the major microsomal steroid hormone 6beta-hydroxylase cytochrome P-450 enzyme. Arch. Biochem. Biophys. 263, 424-436.

11. Waxman, D.J., Lapenson, D.P., Aoyama, T., Gelboin, H.V. and Gonzalez, FJ. 1991. Steroid hormone hydroxylase specificities of eleven cDNA-expressed human cytochrome P-450s. Arch. Biochem. Biophys. 290, 160-166.

12. Rebbeck, T.R. 1998. Characterization of an allelic variant in the nifedipine-specific element of CYP3A4: ethnic distribution and implications for prostate cancer risk. Mutations in brief no. 191. Online. Human Mutation 12, 289-292.
13. Rebbeck, T.R., Jaffe, J.M., Walker, A.H. and Wein, A.J. 1998. Modification of clinical presentation of prostate tumors by a novel genetic variant in CYP3A4. J. Nat. Cancer Inst. 90, 1225-1229.

14. Westlind, A., Lofberg, L., Tindberg, N. and Andersson, T.B. 1999. Inter-individual differences in hepatic expression of CYP3A4: relationship to genetic polymorphism in the 5'upstream regulatory region. Biochem. Biophys. Res. Commun. 259, 201-205.

15. Wandel, C., Witte, J.S., Hall, J.M., Stein, C.M. and Wood, A.J. 2000. CYP3A activity in African American and European American men: population differences and functional effect of the CYP3A4*1B5'-promoter region polymorphism. Clin. Pharmacol. Ther. 68, 82-91.

16. Ando, Y., Tateishi, T., Sekido, Y., Yamamoto, T., Satoh, T. and Hasegawa, Y. 1999. Re: Modification of clinical presentation of prostate tumors by a novel genetic variant in CYP3A4. J. Nat. Cancer Inst. 91, 1587-1590.

17. Ball, S.E., Scatina, J., Kao, J., Ferron, G.M., Fruncillo, R. and Mayer, P. 1999. Population distribution and effects on drug metabolism of a genetic variant in the 5 ' promoter region of CYP3A4. Clin. Pharmacol. Ther. 66, 288-294.

18. Paris, P.L., Kupelian, P.A., Hall, J.M., Williams, T.L., Levin, H. and Klein, E.A. 1999. Association between a CYP3A4 genetic variant and clinical presentation in African-American prostate cancer patients. Cancer Epidemiol. Biomarkers Prev. 8, 901-905.

19. Tayeb, M.T., Clark, C., Sharp, L., Haites, N.E., Rooney, P.H. and Murray, G.I. 2002. CYP3A4 promoter variant is associated with prostate cancer risk in men with benign prostate hyperplasia. Oncol. Rep. 9, 653-655.

20. Plummer, S.J., Conti, D.V., Paris, P.L., Curran, A.P. and Casey, G. 2003. CYP3A4 and CYP3A5 genotypes, haplotypes, and risk of prostate cancer. Cancer Epidemiol. Biomarkers Prev. 12, 928-932.

21. Lee, J.S., Cheong, H.S., Kim, L.H., Kim, J.O., Seo, D.W. and Kim, Y.H. 2013. Screening of Genetic Polymorphisms of CYP3A4 and CYP3A5 Genes. Korean J. Physiol. Pharmacol. 17, 479-484.

22. National Collaborating Centre for Cancer (NICE, UK). 2008. Prostate Cancer: Diagnosis and Treatment. Cardiff (UK): National Collaborating Centre for Cancer (UK).

23. Heidenreich, A., Bastian, P.J., Bellmunt, J., Bolla, M., Joniau, S. and Van, der, Kwast, T. 2014. EAU guidelines on prostate cancer. Part 1: screening, diagnosis, and local treatment with curative intent-update 2013. Eur. Urol. 65, 124-137.

24. Gleason, DF. 1992. Histologic grading of prostate cancer: a perspective. Hum. Pathol. 23, 273-279. 
25. Paris, P.L., Witte, J.S., Kupelian, P.A., Levin, H., Klein, E.A. and Catalona, W.J. 2000. Identification and fine mapping of a region showing a high frequency of allelic imbalance on chromosome 16q23.2 That Corresponds to a Prostate Cancer Susceptibility Locus. Cancer Res. 60, 3645-3649.

26. The Helsinki Declaration of the World Medical Association (WMA). 2014. Ethical principles of medical research involving human subjects. Pol. Merkur. Lekarski. 36, 298301.

27. Islam, M.S., Ahmed, M.U., Sayeed, M.S., Maruf, A.A., Mostofa, A.G. and Hussain, S.M. 2013. Lung cancer risk in relation to nicotinic acetylcholine receptor, CYP2A6 and CYP1A1 genotypes in the Bangladeshi population. Clin. Chim. Acta, 416, 11-9.

28. Al Maruf A., Ahmed, M.U., Yasmin, H., Ullah, M.A., Azad, M.A. and Daly, A.K. 2011. Genotypes and phenotypes of CYP3A in Bangladeshi population. Clin. Chim. Acta 412, 531-536.

29. Daly, A.K., Monkman, S.C., Smart, J. and Steward, A. 1998. Analysis of cytochrome P-450 polymorphisms. Methods Mol. Biol. 107, 405-422.

30. Islam, M.S., Mostofa, A.G., Ahmed, M.U., Bin, Sayeed M.S. and Hasnat, A. 2014. Association of CYP3A4, CYP3A5 polymorphisms with lung cancer risk in Bangladeshi population. Tumor. Biol.35, 1671-1678.

31. Kuehl, P., Zhang, J., Lin, Y., Lamba, J., Assem, M. and Schuetz, J. 2001. Sequence diversity in CYP3A promoters and characterization of the genetic basis of polymorphic CYP3A5 expression. Nat. Genet. 27, 383-391.

32. Sailaja. K., Rao, D.N., Rao, D.R. and Vishnupriya, S. 2010. Analysis of CYP3A5*3 and CYP3A5*6 gene polymorphisms in Indian chronic myeloid leukemia patients. Asian Pac. J. Cancer Prev. 11, 781-784.

33. Van, Schaik, R.H. 2005. Cancer treatment and pharmacogenetics of cytochrome P-450 enzymes. Invest New Drugs, 23, 513-522.

34. Zeigler-Johnson, C., Friebel, T., Walker, A.H., Wang, Y., Spangler, E. and Panossian, S. 2004. CYP3A4, CYP3A5, and CYP3A43 genotypes and haplotypes in the etiology and severity of prostate cancer. Cancer Res, 64, 8461-8467.
35. Nogal, A., Coelho, A., Catarino, R., Morais, A. and Lobo, F. 2007. The CYP3A4 *1B polymorphism and prostate cancer susceptibility in a Portuguese population. Cancer Gene. Cytogenet. 177, 149-152.

36. Fernandez, P., Zeigler-Johnson, C.M., Spangler, E., Van, der, Merwe, A., Jalloh, M. and Gueye, S.M. 2012. Androgen metabolism gene polymorphisms, associations with prostate cancer risk and pathological characteristics: A comparative analysis between South African and Senegalese Men. Prostate Cancer; article ID 798634.

37. Amirimani, B., Walker, A.H., Weber, B.L. And Rebbeck, T.R. 1999. RESPONSE: re: modification of clinical presentation of prostate tumors by a novel genetic variant in CYP3 A4. J. Nat. Cancer Inst. 91, 1588-1590.

38. Spurdle, A.B., Goodwin, B., Hodgson, E., Hopper, J.L., Chen, X. and Purdie, D.M. 2002. The CYP3A4*1B polymorphism has no functional significance and is not associated with risk of breast or ovarian cancer. Pharmacogenetics 12, 355-366.

39. Floyd, M.D., Gervasini, G., Masica, A.L., Mayo, G., George, A.L. and Jr, Bhat, K. 2003. Genotype-phenotype associations for common CYP3A4 and CYP3A5 variants in the basal and induced metabolism of midazolam in European- and AfricanAmerican men and women. Pharmacogenetics 13, 595-606.

40. Amirimani, B., Ning, B., Deitz, A.C., Weber, B.L. and Kadlubar, F.F. 2003. Increased transcriptional activity of the CYP3A4*1B promoter variant. Environ Mol. Mutagen. 42, 299-305.

41. Hamzeiy, H., Bombail, V., Plant, N. and Gibson, G. 2003. Transcriptional regulation of cytochrome P4503A4 gene expression: effects of inherited mutations in the 5'-flanking region. Xenobiotica 33, 1085-1095.

42. Vaarala, M.H., Mattila, H., Ohtonen, P., Tammela, T.L. and Paavonen, T.K. 2008. The interaction of CYP3A5 polymorphisms along the androgen metabolism pathway in prostate cancer. Int. J. Cancer 122, 2511-2516.

43. Zhenhua, L., Tsuchiya, N., Narita, S., Inoue, T., Horikawa, Y. and Kakinuma, H. 2005. CYP3A5 gene polymorphism and risk of prostate cancer in a Japanese population. Cancer Lett. 225, 237-243. 